\title{
Electrodeposition and Characterization of Nanocrystalline Ni-Fe Alloys
}

\author{
R. Abdel-Karim, ${ }^{1}$ Y. Reda, ${ }^{1}$ M. Muhammed, ${ }^{2}$ S. El-Raghy, ${ }^{1}$ M. Shoeib, ${ }^{3}$ and H. Ahmed ${ }^{1}$ \\ ${ }^{1}$ Department of Metallurgy, Faculty of Engineering, Cairo University, Giza 12613, Egypt \\ ${ }^{2}$ Functional Materials Division, Royal Institute of Technology, 16440, Stockholm, Sweden \\ ${ }^{3}$ Metals Technology Department, Central Metallurgical Research \& Development Institute (CMRDI), El-Tebbin, Helwan 11421, Egypt
}

Correspondence should be addressed to R. Abdel-Karim, randaabdelkarim@gmail.com

Received 20 November 2010; Accepted 19 January 2011

Academic Editor: Donglu Shi

Copyright (C) 2011 R. Abdel-Karim et al. This is an open access article distributed under the Creative Commons Attribution License, which permits unrestricted use, distribution, and reproduction in any medium, provided the original work is properly cited.

Nanocrystalline Ni-Fe deposits with different composition and grain sizes were fabricated by electrodeposition. Deposits with iron contents in the range from 7 to $31 \%$ were obtained by changing the $\mathrm{Ni}^{2+} / \mathrm{Fe}^{2+}$ mass ratio in the electrolyte. The deposits were found to be nanocrystalline with average grain size in the range $20-30 \mathrm{~nm}$. The surface morphology was found to be dependent on $\mathrm{Ni}^{2+} / \mathrm{Fe}^{2+}$ mass ratio as well as electroplating time. The grains size decreased with increasing the iron content, especially in case of short time electroplating. Increasing the electroplating time had no significant effect on grain size. The microhardness of the materials followed the regular Hall-Petch relationship with a maximum value $(762 \mathrm{Hv})$ when applying $\mathrm{Ni}^{2+} / \mathrm{Fe}^{2+}$ mass ratio equal to 9.8 .

\section{Introduction}

Ni-Fe alloys ranging in composition from Ni-rich Premalloy to the iron-rich Invar have variety of high technology applications due to their wide spectrum of properties. Due to their unique low coefficient of thermal expansion (CTE) and soft magnetic properties, nickel-iron alloys have been used in industrial applications for over 100 years. Typical examples of applications that are based on the low CTE of Ni-Fe alloys include thermostatic bimetals, glass sealing, integrated circuit packing, cathode ray tube shadow masks, and composites molds/tooling and membranes for liquid natural gas tankers. Applications based on soft magnetic properties include read-write heads for magnetic storage, magnetic actuators, magnetic shielding, and highperformance transformer cores [1].

$\mathrm{Ni}$-Fe systems are fabricated in the form of alloys, multilayers, and nanowires using different techniques such as vacuum evaporation, cold rolling, single-roll rapid quenching, and sputtering electrodeposition [2,3].

Among several methods, electrodeposition is an advantageous method for producing Ni-Fe alloys due to flexibility, low cost, and capability of being used for parts with any size and geometry [4]. Electrolytic growth of metals differs from other methods as it provides the possibility of depositing films with structures different from those formed from vapor phase. Also the electrodeposition technique allows the deposition under normal conditions of temperature and pressure and requires relatively inexpensive equipment [5].

The electrodeposition of Ni-Fe alloys has been studied by several researchers [6-10], and it has been shown that the composition and the grain size of the deposits can be varied by controlling the deposition parameters as well as the electrolyte composition.

The magnetic, mechanical, and corrosion properties of $\mathrm{Ni}-\mathrm{Fe}$ electrodeposits are affected by a number of factors including roughness, grain size, and alloy composition. In turn, these parameters are affected by processing variables such as plating bath chemistry, $\mathrm{pH}$, and temperature as well as the applied current density and electrolyte mixing conditions at the cathode surface [4]. While bath chemistry, $\mathrm{pH}$, and temperature can usually be controlled, significant variations in current density and electrolyte mixing often occur during plating, leading to nonuniformities in deposit composition [11]. 
TABLE 1: Chemical analysis of steel 4130.

\begin{tabular}{lcccccrr}
\hline $\mathrm{C}$ & $\mathrm{P}(\max )$ & $\mathrm{S}(\max )$ & $\mathrm{Mn}$ & $\mathrm{Si}$ & $\mathrm{Mo}$ & $\mathrm{Cr}$ & $\mathrm{Fe}$ \\
\hline $0.28-0.33$ & 0.035 & 0.04 & $0.4-0.6$ & $0.2-0.35$ & $0.15-0.25$ & $0.8-1.1$ & rem \\
\hline
\end{tabular}

TABLE 2: Electroplating bath and electroplating conditions.

\begin{tabular}{|c|c|c|c|c|c|c|c|c|c|c|}
\hline \multicolumn{2}{|c|}{ Composition and working conditions } & 1 & 2 & 3 & 4 & 5 & 6 & 7 & 8 & 9 \\
\hline \multirow{5}{*}{ Composition (g/L) } & $\mathrm{NiCl}_{2} \cdot 6 \mathrm{H}_{2} \mathrm{O}$ & \multicolumn{9}{|c|}{23.5} \\
\hline & $\mathrm{FeCl}_{2} \cdot 6 \mathrm{H}_{2} \mathrm{O}$ & & 1 & & \multicolumn{3}{|c|}{1.5} & \multicolumn{3}{|c|}{2.1} \\
\hline & $\mathrm{Ni}^{2+} / \mathrm{Fe}^{2+}$ mass ratio & & 20.7 & & \multicolumn{3}{|c|}{13.8} & \multicolumn{3}{|c|}{9.8} \\
\hline & $\mathrm{H}_{3} \mathrm{BO}_{3}$ & \multicolumn{9}{|c|}{25} \\
\hline & Time (min) & 25 & 50 & 100 & 25 & 50 & 100 & 25 & 50 & 100 \\
\hline \multirow{4}{*}{ Working conditions } & Temperature (C) & \multicolumn{9}{|c|}{$55.5 \pm 2$} \\
\hline & $\mathrm{pH}$ & \multicolumn{9}{|c|}{2.5} \\
\hline & Agitating method & \multicolumn{9}{|c|}{ Magnetic stirrer } \\
\hline & Current density $\left(\mathrm{mA} / \mathrm{cm}^{2}\right)$ & \multicolumn{9}{|c|}{20} \\
\hline
\end{tabular}

A better understanding of nanocrystalline Ni-Fe deposits is a critical step in developing these new materials. The aim of this work is to prepare nanostructured Ni-Fe electrodeposits $(7-31 \% \mathrm{Fe})$ relatively thicker (in $\mu \mathrm{m}$ scale) than those reported in the literature with detailed surface analysis and morphology of using XRD, SEM, and EDX techniques. The effect of process parameters; namely, iron content in the electrolytic bath as well as electroplating time, will be studied.

\section{Experimental Techniques}

$\mathrm{Ni}$-Fe deposits with different iron contents were prepared using electrochemical deposition process. Carbon steel 4130 samples of the chemical analysis shown in Table 1, with dimensions $18 \mathrm{~mm} \times 75 \mathrm{~mm}$ and $0.5 \mathrm{~mm}$ thickness, were used as cathode, while the anode was electrolytic nickel. The electroplating solutions used were a modified Watts nickel bath containing a fixed amount of $\mathrm{NiCl}_{2} \cdot 6 \mathrm{H}_{2} \mathrm{O}, \mathrm{FeCl}_{2} \cdot 6 \mathrm{H}_{2} \mathrm{O}$ (source of iron), and sodium citrate (complexing agent), dissolved in double distilled water. In order to make the NiFe alloys firmly adhered to the substrate, the stress between them must be reduced. The refinement of the grain size of the plating can effectively decrease the stress, and this can be achieved by the addition of saccharin to the electrolytes [12].

$\mathrm{Ni}-\mathrm{Fe}$ alloys were deposited under galvanostatic conditions on the 4130 steel substrate for durations 25, 50, and $100 \mathrm{~min}$. The amount of iron in the deposit was varied by changing the $\mathrm{Ni}^{2+} / \mathrm{Fe}^{2+}$ ratio. The plating took place at constant stirring speed $(500 \mathrm{rpm})$, by applying current density at $20 \mathrm{~mA} / \mathrm{cm}^{2}$ using Kocour $5 \mathrm{c}$ rectifier. The $\mathrm{pH}$ was kept at 2 by adding a few drops of sulfuric acid. The $\mathrm{pH}$ and the composition of electrolytes were based on previous work [13]. Chemical composition of electrolytic bath per 1 liter as well as deposition parameters is illustrated in Table 2.
For surface preparation before electroplating, the steel specimens were firstly grinded with 2400 grit SiC, rinsed with distilled water, degreased in perchloroethylene, and then rinsed with distilled water. These steps were followed by pickling in hydrochloric acid of (15\% conc.) for 5 to 10 seconds, rinsing with distilled water and drying using hot dry air. The layers thickness obtained ranged from 140 to $230 \mu \mathrm{m}$.

The surface morphology of the films was examined with SEM type JEOL JXA-840A. Additional investigation at higher magnifications (100-120 kx) was conducted using ULTRA 55 (ZEISS) field emission SEM. The chemical composition of the films obtained was determined using the EDX analyzer attachment.

The structural analysis of the films was carried out using a computer-controlled Shimadzu X-ray diffractometer employing $\mathrm{CuK}$ radiation. The grain size was calculated from XRD patterns, using Sherrer formulation. The microhardness $\mathrm{Hv}_{0.3}$ of the electrodeposits was determined as the average of 10 to 15 measurements per deposit using a Shimadzu HMV-2T microhardness tester with a load of $2.942 \mathrm{~N}$.

\section{Results}

3.1. Morphology of the Deposits. The SEM micrographs of different Ni-Fe deposits are shown in Figures 1-3. The formation of these layers is uniform in nature without any damage. The surface morphology was found to be dependent on $\mathrm{Ni}^{2+} / \mathrm{Fe}^{2+}$ mass ratio as well as electroplating time.

Figure 1 shows SEM of electrodeposited Ni base layers at deposition time $25 \mathrm{~min}$ as a function of $\mathrm{Ni}^{2+} / \mathrm{Fe}^{2+}$ mass ratio of the electrolytic bath. Figure 1(a), for sample of $\mathrm{Ni}^{2+} / \mathrm{Fe}^{2+}$ mass ratio 20.7, displayed a typical elliptical particles shape, with the larger particles growing preferentially out of the surface. By increasing the iron content (Figure 1(b)), samples of $\mathrm{Ni}^{2+} / \mathrm{Fe}^{2+}$ mass ratio 13.8 showed clusters of spherical fine 


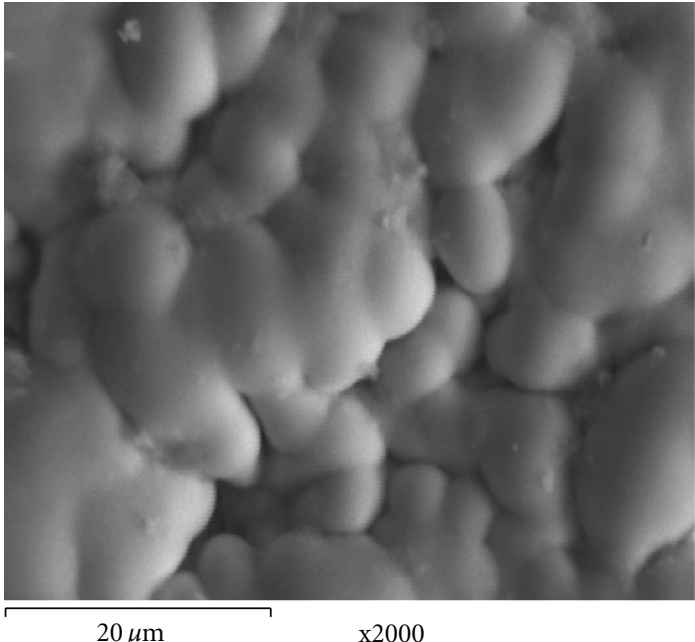

(a) $\mathrm{Ni}^{2+} / \mathrm{Fe}^{2+}$ mass ratio 20.7

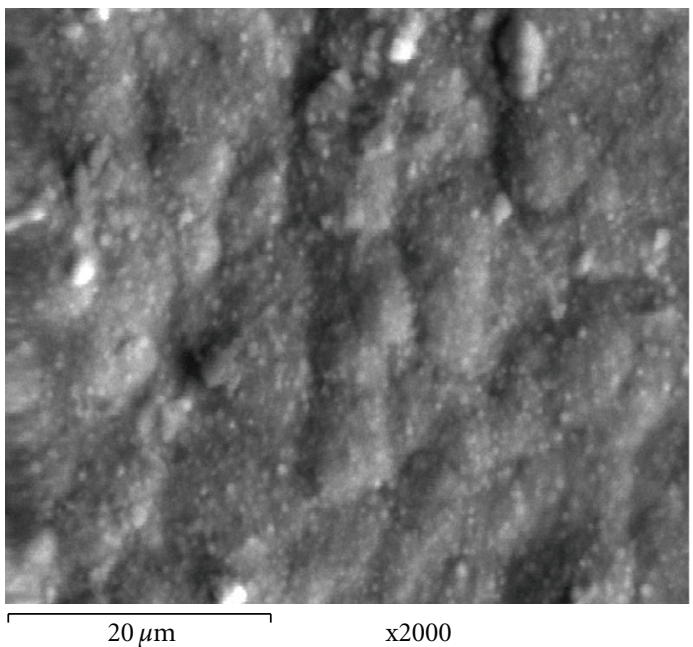

(b) $\mathrm{Ni}^{2+} / \mathrm{Fe}^{2+}$ mass ratio 13.8

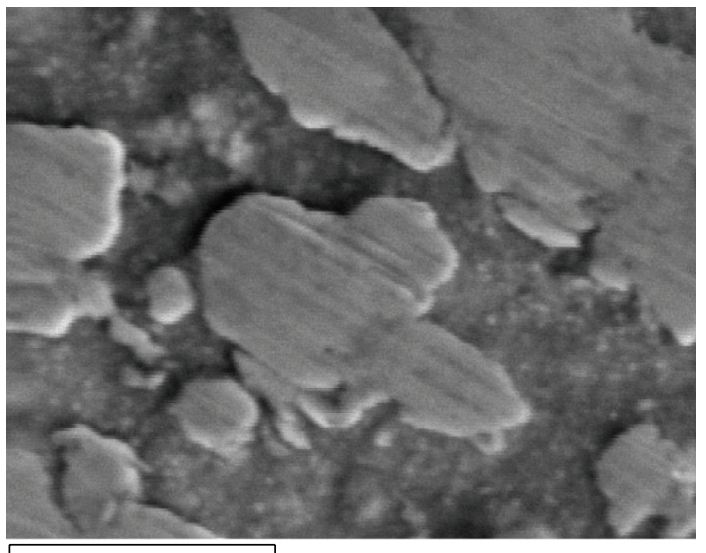

$20 \mu \mathrm{m}$ x 2000

(c) $\mathrm{Ni}^{2+} / \mathrm{Fe}^{2+}$ mass ratio 9.8

FIGURE 1: SEM of electrodeposited Ni base layers at current density $20 \mathrm{~mA} / \mathrm{cm}^{2}$ and deposition time $25 \mathrm{~min}$ as a function of $\mathrm{Ni}^{2+} / \mathrm{Fe}^{2+} \mathrm{mass}$ ratio in the electrolytic bath-2000x.

particles embedded in elongated coarse ones with appearance of grain boundaries. For samples prepared by using $\mathrm{Ni}^{2+} / \mathrm{Fe}^{2+}$ mass ratio of 9.8 (Figure $1(\mathrm{c})$ ), the microstructure is made of flattened areas containing very fine particles distributed all over the surface.

Figure 2 shows the effect of $\mathrm{Ni}^{2+} / \mathrm{Fe}^{2+}$ ratio on the morphologies of electrodeposited $\mathrm{Ni}$ base layer with deposition time of 50 min. In case of $\mathrm{Ni}^{2+} / \mathrm{Fe}^{2+}$ mass ratio equal to 20.7 (Figure 2(a)), typical elongated elliptical clusters, similar to samples electrodeposited for $25 \mathrm{~min}$. Meanwhile, using $\mathrm{Ni}^{2+} / \mathrm{Fe}^{2+}$ mass ratio in the order of 13.8 , samples showed very fine nodular particles uniformly distributed all over the surface. These nanocrystalline particles with some flattened areas can be better seen by using higher magnification (120000x), as illustrated in Figure 2(c). By increasing the iron content and consequently decreasing the $\mathrm{Ni}^{2+} / \mathrm{Fe}^{2+}$ mass ratio down to 9.8 (Figure 2(d)), the morphology changed into clusters of fine particles. Some cracks can be seen, indicating the presence of internal stresses.
Figure 3 represents SEM of electrodeposited Ni base layers at longer electrodeposition time $(100 \mathrm{~min})$ as a function of $\mathrm{Ni}^{2+} / \mathrm{Fe}^{2+}$ mass ratio in the electrolytic bath. From Figure 3(a), in case of $\mathrm{Ni}^{2+} / \mathrm{Fe}^{2+}$ mass ratio equal to 20.7, SEM image displayed well defined nodular coarse and fine particles with no appearance of grain boundaries. This nanosized particles can be better illustrated by using higher magnification (100000x), as shown in Figure 3(b). On the other hand, from Figure 3(c), sample of $\mathrm{Ni}^{2+} / \mathrm{Fe}^{2+}$ mass ratio equal to 13.8 displayed clusters of fine particles embedded in elongated elliptical ones and some grain boundaries can be seen. By raising the iron content and thus decreasing the $\mathrm{Ni}^{2+} / \mathrm{Fe}^{2+}$ mass ratio down to 9.8 (Figure 3(d)), the surface morphology showed rough cauliflower structure. The cauliflower morphology particle is made of coagulate particle distributed all over the surface with a flattened grains, as mentioned by Daojiong [14].

It can be concluded that increasing the iron content of the bath led to formation of well-defined nodular particles 


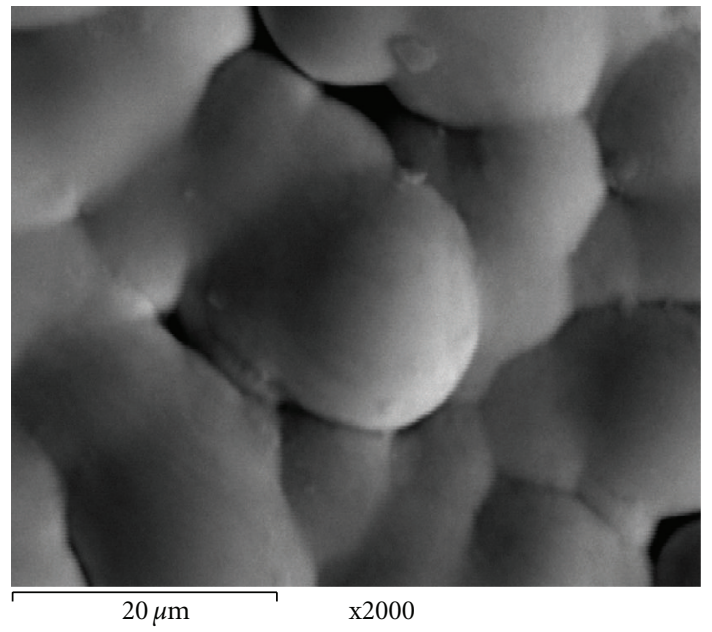

(a) $\mathrm{Ni}^{2+} / \mathrm{Fe}^{2+}$ mass ratio $20.72000 \mathrm{x}$

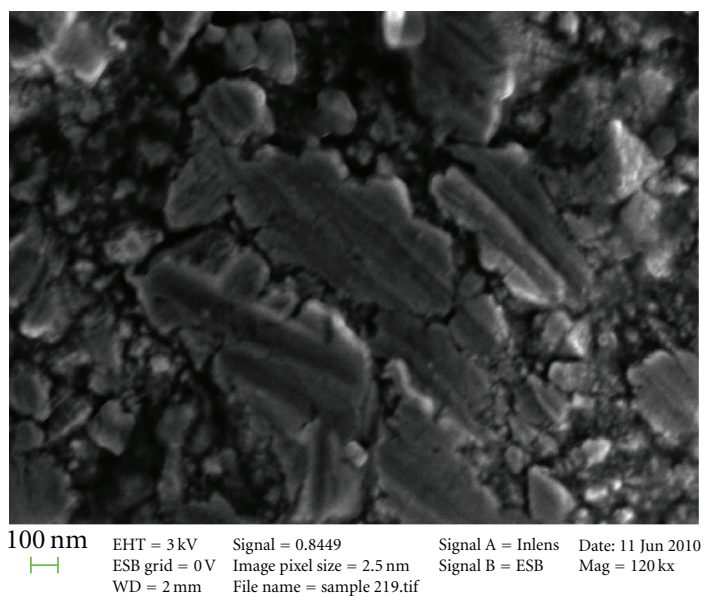

(c) $\mathrm{Ni}^{2+} / \mathrm{Fe}^{2+}$ mass ratio $13.8120000 \mathrm{x}$

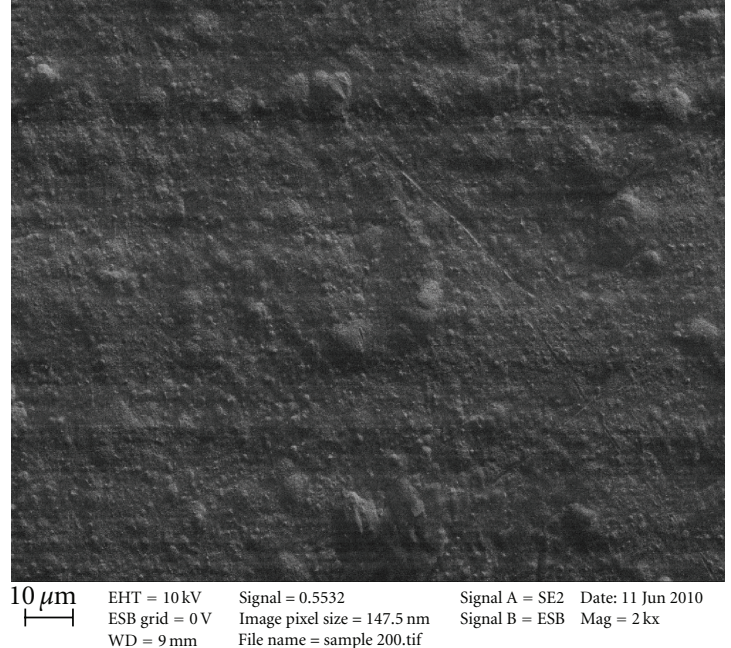

(b) $\mathrm{Ni}^{2+} / \mathrm{Fe}^{2+}$ mass ratio $13.82000 \mathrm{x}$

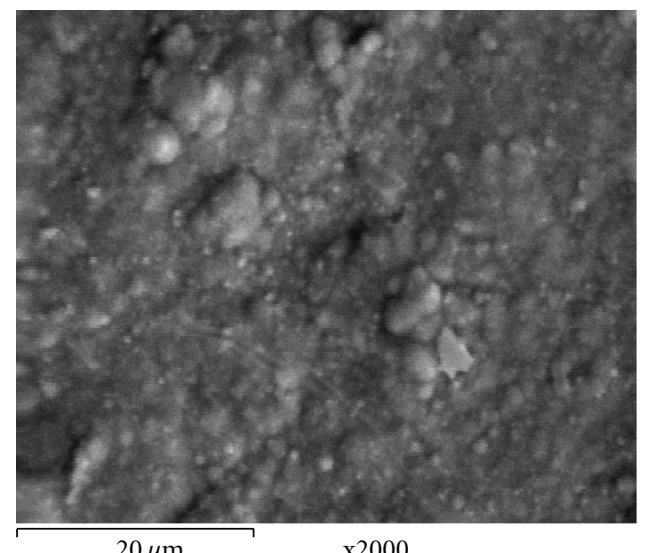

(d) $\mathrm{Ni}^{2+} / \mathrm{Fe}^{2+}$ mass ratio $9.82000 \mathrm{x}$

FIGURE 2: SEM of electrodeposited Ni base layers at current density $20 \mathrm{~mA} / \mathrm{cm}^{2}$ and deposition time $50 \mathrm{~min}$ as a function of $\mathrm{Ni}^{2+} / \mathrm{Fe}^{2+}$ mass ratio in the electrolytic bath.

with finer size. Increasing the electroplating time had no significant effect on particle size.

Some cracks were detected (Figure 3(d)) indicating the generation of internal stresses. The internal stresses are due to one layer of electrodeposited atoms fitting the one beneath it and subsequently shrinking or expanding, or the layer of atoms being deposited in either compression or tension in order to fit. Theories proposed to explain these stressraising conditions are classified as crystalline-joining theory, hydrogen theory, excess energy theory, and lattice defect theory [15].

3.2. EDX Analysis. The average composition of all alloys was evaluated by EDX microanalysis, whose results are given in Table 3 which indicates that oxygen was detected in electrodeposited layers. It can be mentioned that metallic alloys and their oxides were produced simultaneously during the electrochemical reduction process. Iron content values between 7 and $31.55 \%$ were obtained. The oxygen content of the deposit increased with increasing the iron content.

Figure 4 shows the dependence of $\mathrm{Fe}$ deposit content on the bath $\mathrm{Ni} / \mathrm{Fe}$ weight ratio. For high $\mathrm{Ni}^{2+} / \mathrm{Fe}^{2+}$ ratio (equal to 21.7) and electroplating time $25 \mathrm{~min}$, the Fe deposit content is measured to be $10.49 \%$ with $\mathrm{Ni}$ content equal to $81.65 \%$. The iron content in the deposit has sharply increased to $31.55 \%$, while the $\mathrm{Ni}$ deposit content is obtained to be $52.19 \%$, with decreasing $\mathrm{Ni}^{2+} / \mathrm{Fe}^{2+}$ ratio from 21.7 to 9.8 . The same trend was observed at electroplating time 50 as well as $100 \mathrm{~min}$.

3.3. X-Ray Diffraction Analysis. X-ray diffraction patterns (XRD) for all cases indicated the presence of sharp peaks, which reveals that the film is crystalline in nature. One example of XRD patterns for Ni-Fe deposits is shown in Figure 5. The peaks corresponding to (111) at $2 \theta=44-44.5^{\circ}$, (200) and (220) were observed in all films, which correspond 


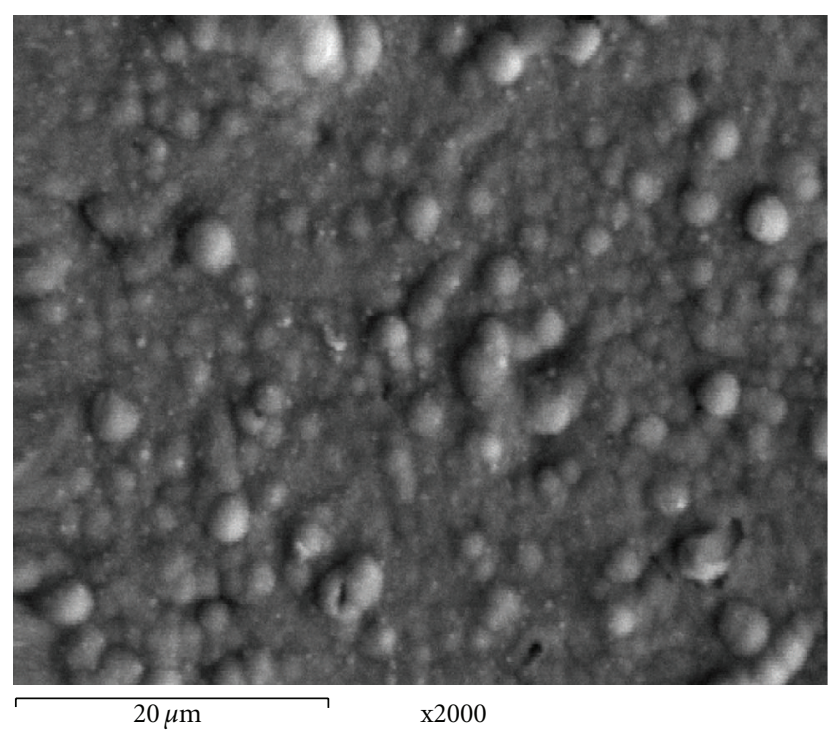

(a) $\mathrm{Ni}^{2+} / \mathrm{Fe}^{2+}$ mass ratio $20.72000 \mathrm{x}$

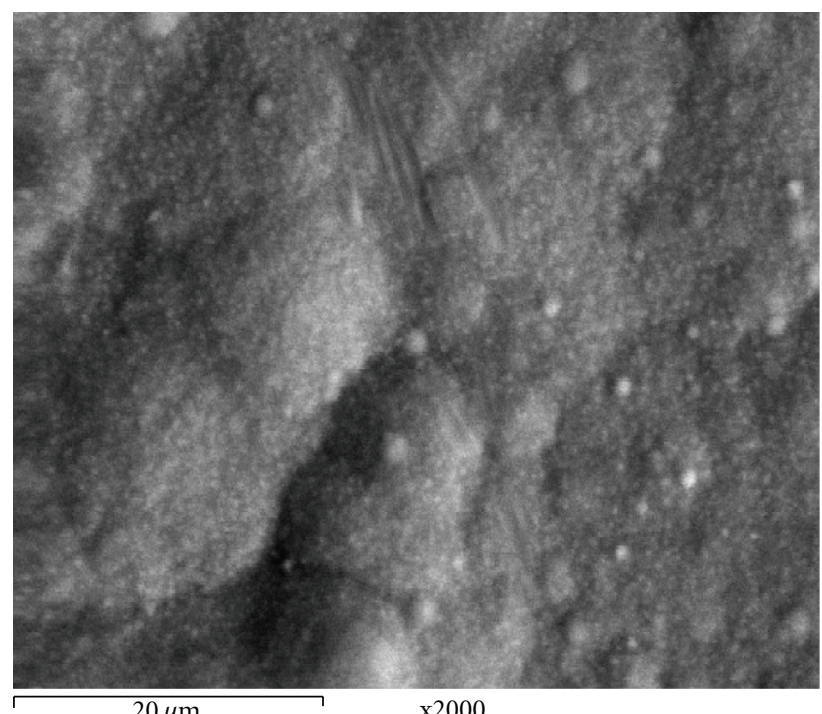

$20 \mu \mathrm{m}$

(c) $\mathrm{Ni}^{2+} / \mathrm{Fe}^{2+}$ mass ratio $13.82000 \mathrm{x}$

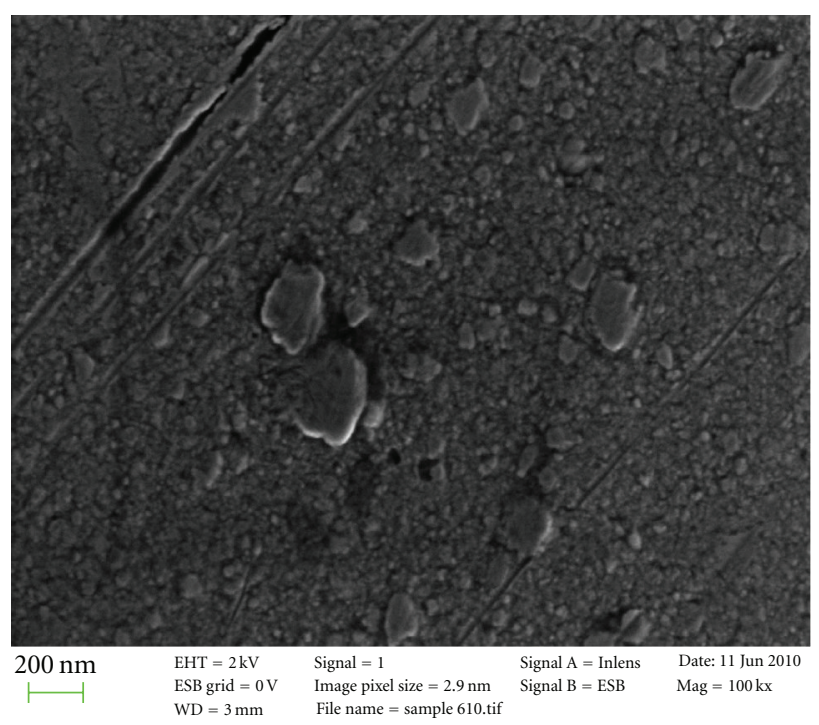

(b) $\mathrm{Ni}^{2+} / \mathrm{Fe}^{2+}$ mass ratio $20.7100000 \mathrm{x}$

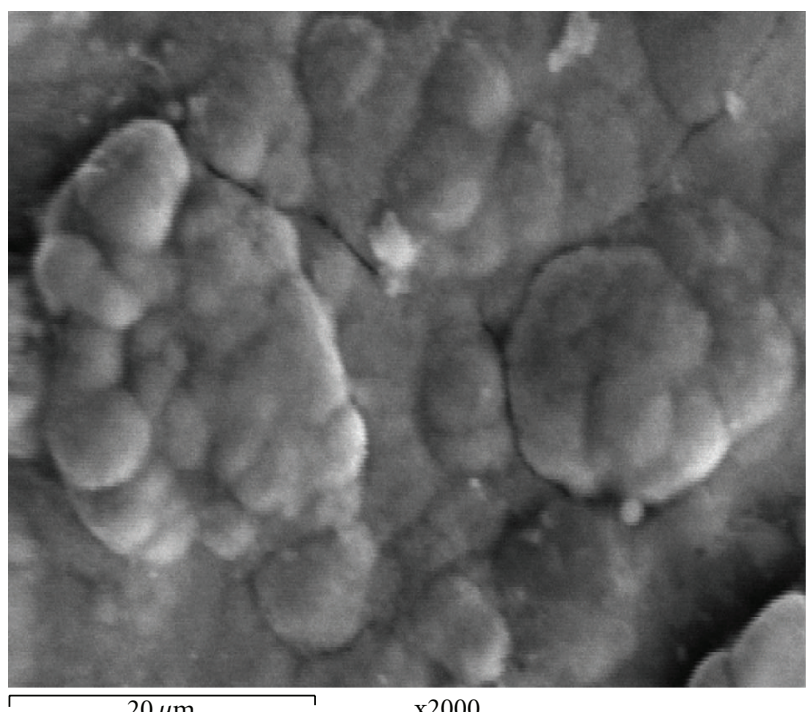

(d) $\mathrm{Ni}^{2+} / \mathrm{Fe}^{2+}$ mass ratio $9.82000 \mathrm{x}$

Figure 3: SEM of electrodeposited Ni-Fe elect layers at current density $20 \mathrm{~mA} / \mathrm{cm}^{2}$ and deposition time $100 \mathrm{~min}$ as a function of $\mathrm{Ni}^{2+} / \mathrm{Fe}^{2+}$ mass ratio in the electrolytic bath.

to FCC structure, namely, Ni-Fe solid solution (ss). These results are in agreement with previous works [16-18]. It must be mentioned that, for the diffraction angel $2 \theta=43.6^{\circ}$, a smaller peak corresponds to $\mathrm{Ni}_{3} \mathrm{Fe}$ phase with $\mathrm{BCC}$ structure [3].

Table 4 shows the effect of further increasing the deposition time as well as iron content on the weight percentages of detected phases. Generally, increasing the iron content and electroplating time leads to decreasing \% $\mathrm{Ni}$ (ss) and consequently increasing $\% \mathrm{Ni}_{3} \mathrm{Fe}$ content in the deposited layer. For example, at electroplating time $25 \mathrm{~min}$, the XRD pattern shows alloys deposited containing $63 \% \mathrm{Ni}$ (ss) and $45 \%$ for $\mathrm{Ni}^{2+} / \mathrm{Fe}^{2+}$ ratios equal to 20.7 and 9.8 , respectively. For longer electroplating time 100 min and $\mathrm{Ni}^{2+} / \mathrm{Fe}^{2+}$ ratio equal to 9.8, alloy deposited contained $37 \% \mathrm{Ni}$ (ss) and $63 \% \mathrm{Ni}_{3} \mathrm{Fe}$.

The crystalline grain sizes obtained at (111) XRD peaks were calculated using Scherrer's formula. Crystalline grain sizes between 20 and $33 \mathrm{~nm}$ could be detected. Figure 6 shows the particle size as a function of $\mathrm{Fe}$ content on the electrodeposition bath at various deposition times. A pronounced grain refining effect of iron was detected especially in case of short deposition time ( $25 \mathrm{~min})$. It is thus suggested that low $\mathrm{pH}$ (equal to 2 ) and high concentration of Fe resulted in grain refining effect of the deposited layers. This refining effect of iron is in agreement with results of previous works [19-21]. 
TABLE 3: EDX analysis of electrodeposited Ni-Fe layers.

\begin{tabular}{|c|c|c|c|c|c|}
\hline \multicolumn{3}{|c|}{ Process conditions } & \multicolumn{3}{|c|}{ Chemical analysis, $\%$} \\
\hline $\mathrm{Fe}, \mathrm{gm}^{*}$ & $\begin{array}{l}\mathrm{Ni}^{2+} / \mathrm{Fe}^{2+} \\
\text { mass ratio }\end{array}$ & Time, $\min$ & $\mathrm{O}$ & $\mathrm{Fe}$ & $\mathrm{Ni}$ \\
\hline 1 & 20.7 & & 7.85 & 10.49 & 81.65 \\
\hline 1.5 & 13.8 & 25 & 0.66 & 12.77 & 86.58 \\
\hline 2.1 & 9.8 & & 16.26 & 31.55 & 52.19 \\
\hline 1 & 20.7 & & 7.85 & 10.49 & 81.65 \\
\hline 1.5 & 13.8 & 50 & 22.48 & 27.07 & 50.45 \\
\hline 2.1 & 9.8 & & & n.a & \\
\hline 1 & 20.7 & & 1.47 & 7.70 & 90.83 \\
\hline 1.5 & 13.8 & 100 & & n.a & \\
\hline 2.1 & 9.8 & & 27.37 & 28.21 & 44.42 \\
\hline
\end{tabular}

${ }^{*}$ In the form of $\mathrm{FeCl}_{2} \cdot 6 \mathrm{H}_{2} \mathrm{O}$.

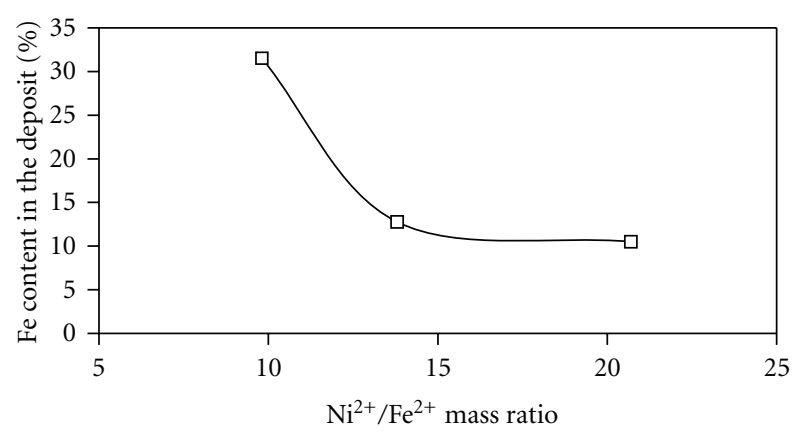

Figure 4: Relationship between iron content in the electrolytic bath and iron content in the electrodeposited Ni-Fe layers, time $25 \mathrm{~min}$.

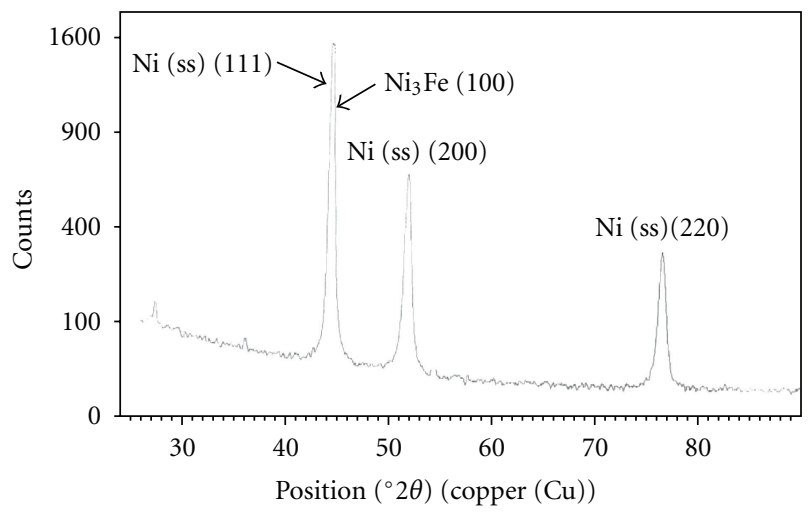

Figure 5: XRD pattern for Ni-Fe deposited layer using $\mathrm{Ni}^{2+} / \mathrm{Fe}^{2+}$ ratio equal to 20.7 .

3.4. Microhardness. The measured microhardness values as a function of $\mathrm{Ni}^{2+} / \mathrm{Fe}^{2+}$ mass ratio as well as deposition time are given in Figure 7. The hardness values were proportional to the iron content in the deposits. For example, microhardness values of 762 and 625 were registered upon using $\mathrm{Ni}^{2+} / \mathrm{Fe}^{2+}$ ratio 9.8 in the electrolytic bath and deposition time $50 \mathrm{~min}$, respectively. The measured values were sharply decreased with further increasing the $\mathrm{Ni}^{2+} / \mathrm{Fe}^{2+}$ ratio.
TABLE 4: XRD characteristics of electroplated Ni-Fe layers.

\begin{tabular}{|c|c|c|c|c|}
\hline \multicolumn{3}{|c|}{ Process conditions } & \multirow{2}{*}{$\% \mathrm{Ni}(\mathrm{ss})$} & \multirow{2}{*}{$\begin{array}{l}\mathrm{Ni}_{3} \mathrm{Fe}, \\
\%\end{array}$} \\
\hline $\mathrm{Fe}, \mathrm{gm}^{*}$ & $\begin{array}{l}\mathrm{Ni}^{2+} / \mathrm{Fe}^{2+} \\
\text { mass ratio }\end{array}$ & Time, min & & \\
\hline 1 & 20.7 & & 63 & 37 \\
\hline 1.5 & 13.8 & 25 & 49 & 51 \\
\hline 2.1 & 9.8 & & 45 & 55 \\
\hline 1 & 20.7 & & 60 & 40 \\
\hline 1.5 & 13.8 & 50 & 46 & 54 \\
\hline 2.1 & 9.8 & & 44 & 56 \\
\hline 1 & 20.7 & & 54 & 46 \\
\hline 1.5 & 13.8 & 100 & 43 & 57 \\
\hline 2.1 & 9.8 & & 37 & 63 \\
\hline
\end{tabular}

* In the form of $\mathrm{FeCl}_{2} \cdot 6 \mathrm{H}_{2} \mathrm{O}$.

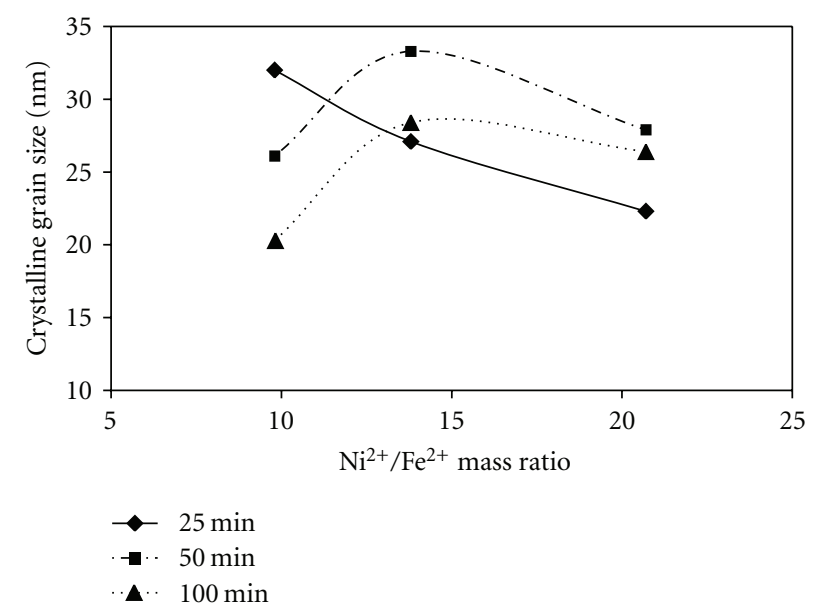

FIGURE 6: Effect of iron content in the electrolytic bath on the crystalline grain size of electrodeposited Ni-Fe layers.

\section{Discussion}

Ni-based deposits with iron contents in the range from 7 to $31 \%$ were obtained by changing the $\mathrm{Ni}^{2+} / \mathrm{Fe}^{2+}$ mass ratio in the electrolyte. Electrodeposition of $\mathrm{Ni}-\mathrm{Fe}$ alloys has attracted considerable attention because it exhibits the phenomenon of anomalous codeposition. This term introduced by Brenner is being used to describe the preferential deposition of less noble material, Fe, to more noble material, $\mathrm{Ni}$. In other words, the reduction of nickel is inhibited while the deposition of iron is enhanced [6].

The composition and properties of electrodeposited NiFe depends on the composition of the solution from which they are plated. By decreasing the $\mathrm{Ni}^{2+} / \mathrm{Fe}^{2+}$ mass ratio in the bath, the iron content decreases and consequently the iron content in the deposits decreases.

In 1960, Dahms claimed that anomalous codeposition occurs when the surface $\mathrm{pH}$ is high enough to cause the formation of ferrous hydroxide, which is adsorbed preferentially on the electrode surface and blocks the deposition of nickel. 


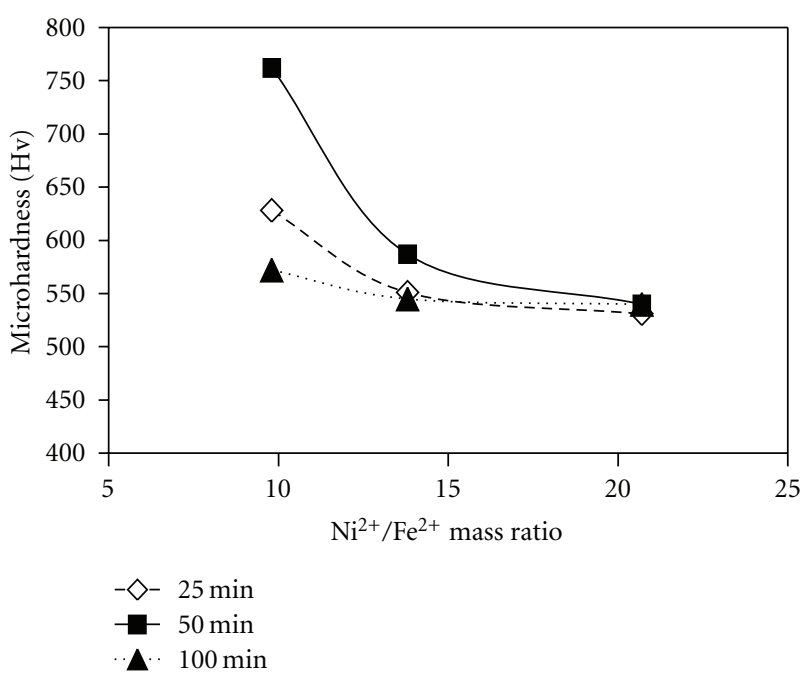

Figure 7: Effect of iron content in the electrolytic bath on the microhardness of electrodeposited Ni-Fe layers.

It was claimed that metal reduction reaction is divided in several steps, as in the following equations, where $\mathrm{M}$ is $\mathrm{Ni}$ or Fe:

$$
\begin{aligned}
& \mathrm{M}^{2+}+\mathrm{OH}^{-}=\mathrm{MOH}^{+}, \\
& \mathrm{MOH}^{+}+\mathrm{e}=\mathrm{MOH}_{\mathrm{ad}}, \\
& \mathrm{MOH}_{\mathrm{ad}}+\mathrm{e}=\mathrm{MOH}^{-} .
\end{aligned}
$$

The reduction reaction rate was restricted with the place where the middle substance is absorbed. Since the discompose constant of $\mathrm{FeOH}^{+}$is smaller than that of $\mathrm{NiOH}^{+}$in the same $\mathrm{pH}$, the partial places of $\mathrm{NiOH}_{\mathrm{ad}}$ on the cathodic surface were occupied by $\mathrm{FeOH}_{\mathrm{ad}}$, in that the nickel ions discharge was restrained. Thus during the process of $\mathrm{Ni}$-Fe codeposition, the iron ions discharge rate was faster than that of nickel ions.

The iron content of the alloy film always increases with the increase of bath $\mathrm{pH}$. The increase of bath $\mathrm{pH}$ favors producing $\mathrm{Fe}(\mathrm{OH})_{2}$, which is adsorbed on the cathodic surface and nickel ions discharge is restrained. Also, the iron content in the film always decreases with the increase of bath temperature. With the rise of the bath temperature, the quick consuming of $\mathrm{FeOH}_{\mathrm{ad}}$ leads to weakening of restrain to nickel ion discharge, thus the rate of nickel discharge increases [22].

According to this work, the electrodeposited nanocrystalline (20-30 nm) Fe-Ni alloys are composed mainly of two phases: $\mathrm{Ni}$ (ss) phase and $\mathrm{Ni}_{3} \mathrm{Fe}$ phase for a wide range of $\mathrm{Ni}^{2+} / \mathrm{Fe}^{2+}$ mass ratio in the bath. The intensity of $\mathrm{Ni}_{3} \mathrm{Fe}$ phase increased with increasing the iron content as well as the deposition time.

A recent study by Chinnasamy et al. [19] suggests that there is a larger probability forming ordered $\mathrm{Ni}_{3} \mathrm{Fe}$ in nanocrystalline nickel-iron alloys due to the faster grain boundary diffusion in comparison with conventional alloys. The crystal structure of $\mathrm{Ni}_{3} \mathrm{Fe}$ is called a supper lattice structure which has a cubic crystal structure composed of three $\mathrm{Ni}$ atoms each of which is located at the center of each cubic face and an Fe atom placed at the corners of the cube [3].
The grain size as well as the composition of the deposits is strongly dependent on the electrolyte composition and deposition parameters. An increase in the $\mathrm{Ni} / \mathrm{Fe}$ ratio of the electrolyte has been reported to simultaneously decrease the iron content of the alloy and increase its grain size [23].

Ebrahimi and Li [24] demonstrated that the electrodeposition of nickel and iron and nickel-iron alloys is a diffusioncontrolled process with a typical nucleation mechanism. The current transients reveal that the nucleation mechanism is instantaneous with a typical three-dimensional nucleation and growth process.

According to the classical theories on electrochemical phase formation and growth, the three-dimensional nucleation rate, $j$, is given by

$$
J=K_{1} \exp \left[-\frac{4 B V_{m}^{2} \sigma^{3}}{27}(z e \eta)^{2} K T\right],
$$

where $K_{1}$ is the rate constant, $B$ the geometric factor, $V_{m}$ the area occupied by one atom, $\sigma$ the average specific surface energy, $z$ the electronic charge of the ion, $e$ the charge of electron, $K$ Boltzmann constant, and $\eta$ the over potential.

A higher $\mathrm{pH}$ decreased the activation and diffusion polarization, decreasing the total over potential for the alloy electrodeposition. The number of nucleation sites is increased as the over potential and the nickel concentration decrease [6]. This can explain the reduction of grain size with decreasing $\mathrm{Ni}^{2+} / \mathrm{Fe}^{2+}$ mass ratio in electrolyte and consequently decreasing the $\mathrm{Ni}$ content of the deposits.

The microhardness of the materials followed the regular Hall-Petch relationship with a maximum value $(762 \mathrm{Hv})$ when applying lower $\mathrm{Ni}^{2+} / \mathrm{Fe}^{2+}$ mass ratio (9.8). High hardness values were detected for higher iron content in the deposits. According to Afshar et al. [25] classical solid solution hardening cannot explain the variation of hardness with iron content observed in this study. The hardening due to the increase in iron content can be attributed to the reduction in grain size. Several factors may be attributed to the variation in hardness including ordering near $\mathrm{Ni}_{3} \mathrm{Fe}$ composition, presence of internal stresses, and the width of the grain size distribution. Yeh et al. [26] stated that, as current density increases, the amounts of Fe precipitation increase, which results in increased hardness. High current density induces formation of $\mathrm{Ni}-\mathrm{Fe}$ alloys having ( 11 1) referred crystallographic orientation and caused higher hardness.

\section{Conclusions}

From this work, it can be concluded that

(1) by decreasing the $\mathrm{Ni}^{2+} / \mathrm{Fe}^{2+}$ mass ratio in the bath, the iron content decreases and consequently the iron content in the deposits decreases,

(2) increasing the iron content of the bath led to formation of well-defined nodular particles with finer size,

(3) increasing the electroplating time had no significant effect on particle size, 
(4) nanocrystalline electrodeposited Fe-Ni alloys are composed mainly of two phases: $\mathrm{Ni}$ (ss) phase and $\mathrm{Ni}_{3} \mathrm{Fe}$ phase for a wide range of $\mathrm{Ni}^{2+} / \mathrm{Fe}^{2+}$ mass ratio in the bath; the intensity of $\mathrm{Ni}_{3} \mathrm{Fe}$ phase increased with increasing the iron content as well as the deposition time,

(5) high hardness values were detected for higher iron content in the deposits.

\section{Acknowledgments}

This work was supported by Cairo University Grants for Scientific Research, 2008-2010. The authors are grateful to Professor Wubeshet Sahle, Royal Institute of Technology, Stockholm, Sweden for his efforts during SEM characterization phase of electrodeposited samples.

\section{References}

[1] J. L. McCrea, G. Palumbo, G. D. Hibbard, and U. Erb, "Properties and applications for electrodeposited nanocrystalline $\mathrm{Fe}$ Ni alloys," Reviews on Advanced Materials Science, vol. 5, no. 3, pp. 252-258, 2003.

[2] L. Tiancheng, L. Zhichao, and L. Peng, "Influence of electroplating conditions on magnetic properties of Fe-36\% wt.\% Ni alooy film," Rare Metals, vol. 25, no. 6, pp. 484-488, 2006.

[3] M. Bedir, Ö. F. Bakkaloğlu, I. H. Karahan, and M. Öztaş, "A study on electrodeposited Ni $x$ Fe $1-x$ alloy films," PramanaJournal of Physics, vol. 66, no. 6, pp. 1093-1104, 2006.

[4] N. Myung, "A study on the electrodeposition of NiFe alloy thin films using chronocoulometry and electrochemical quartz crystal microgravimetry," Bulletin of the Korean Chemical Society, vol. 22, no. 9, pp. 994-998, 2001.

[5] F. R. Bento and L. H. Mascaro, "Electrocrystallisation of FeNi alloys from chloride electrolytes," Surface and Coatings Technology, vol. 201, no. 3-4, pp. 1752-1756, 2006.

[6] M. H. Seo, D. J. Kim, and J. S. Kim, "The effects of $\mathrm{pH}$ and temperature on Ni-Fe-P alloy electrodeposition from a sulfamate bath and the material properties of the deposits," Thin Solid Films, vol. 489, no. 1-2, pp. 122-129, 2005.

[7] S. Sam, G. Fortas, A. Guittoum, N. Gabouze, and S. Djebbar, "Electrodeposition of NiFe films on $\mathrm{Si}\left(\begin{array}{lll}1 & 0 & 0\end{array}\right)$ substrate," Surface Science, vol. 601, no. 18, pp. 4270-4273, 2007.

[8] P. Fricoteaux and C. Rousse, "Influence of substrate, $\mathrm{pH}$ and magnetic field onto composition and current efficiency of electrodeposited Ni-Fe alloys," Journal of Electroanalytical Chemistry, vol. 612, no. 1, pp. 9-14, 2008.

[9] M. M. Ahadian, A. I. zad, E. Nouri, M. Ranjbar, and A. Dolati, "Diffusion and segregation of substrate copper in electrodeposited Ni-Fe thin films," Journal of Alloys and Compounds, vol. 443, no. 1-2, pp. 81-86, 2007.

[10] Z. Zhao, "Electrocrystallization nucleation and growth of NiFe alloys on brass substrate," The Transactions of Nonferrous Metals Society of China, vol. 15, no. 4, pp. 897-901, 2005.

[11] S. D. Leith, S. Ramli, and D. T. Schwartz, "Characterization of $\mathrm{Ni}_{x} \mathrm{Fe}_{1-x}(0.10<x<0.95)$ electrodeposition from a family of sulfamate-chloride electrolytes," Journal of the Electrochemical Society, vol. 146, no. 4, pp. 1431-1435, 1999.
[12] J.-k. Yu, M.-z. Wang, Q. Li, J. Yang, and L. Liu, "Effects of saccharin on microstructure and property of electro-deposited Ni-Fe alloys," Transactions of Nonferrous Metals Society of China, vol. 19, no. 4, pp. 805-809, 2009.

[13] Y. H. Zhang, G. F. Ding, Y. U. L. Cai, H. Wang, and B. Cai, "Electroplating of low stress permalloy for MEMS," Materials Characterization, vol. 57, no. 2, pp. 121-126, 2006.

[14] Z. Daojiong, "Surface structure and catalytic activity of electrodeposited Ni-Fe-Co-Mo alloy electrode by partially leaching Mo and Fe ," The Transactions of Nonferrous Metals Society of China, vol. 16, no. 3, pp. 623-628, 2006.

[15] S. E. Hadian and D. R. Gabe, "Residual stresses in electrodeposits of nickel and nickel-iron alloys," Surface and Coatings Technology, vol. 122, no. 2-3, pp. 118-135, 1999.

[16] P. Esther, C. J. Kennady, and P. Saravanan, "Structural and magnetic properties of electrodeposited Ni-Fe-W thin films," Journal of Solid State Chemistry, vol. 182, no. 10, pp. 27962800, 2009.

[17] S. Sam, G. Fortas, A. Guittoum, N. Gabouze, and S. Djebbar, "Electrodeposition of NiFe films on $\operatorname{Si}\left(\begin{array}{lll}1 & 0 & 0\end{array}\right)$ substrate," Surface Science, vol. 601, no. 18, pp. 4270-4273, 2007.

[18] A. Ispas, H. Matsushima, W. Plieth, and A. Bund, "Influence of a magnetic field on the electrodeposition of nickel-iron alloys," Electrochimica Acta, vol. 52, no. 8, pp. 2785-2795, 2007.

[19] C. N. Chinnasamy, A. Narayanasamy, N. Ponpandian, K. Chattopadhyay, and M. Saravanakumar, "Order-disorder studies and magnetic properties of mechanically alloyed nanocrystalline NiFe alloy," Materials Science and Engineering A, vol. 304-306, no. 1-2, pp. 408-412, 2001.

[20] C. Cheung, F. Djuanda, U. Erb, and G. Palumbo, "Electrodeposition of nanocrystalline Ni-Fe alloys," Nanostructured Materials, vol. 5, no. 5, pp. 513-523, 1995.

[21] C. Cheung, G. Palumbo, and U. Erb, "Synthesis of nanocrystalline permalloy by electrodeposition," Scripta Metallurgica et Materiala, vol. 31, no. 6, pp. 735-740, 1994.

[22] T. Liu, Z. Lu, D. Li et al., "Influence of electroplating conditions on magnetic properties of Fe-36 wt.\% Ni alloy film," Rare Metals, vol. 25, no. 6, pp. 484-488, 2006.

[23] H. Li and F. Ebrahimi, "Synthesis and characterization of electrodeposited nanocrystalline," Materials Science and Engineering A, vol. 347, no. 1-2, pp. 93-101, 2003.

[24] F. Ebrahimi and H. Q. Li, "Structure and properties of electrodeposited nanocrystalline FCC Ni-Fe alloys," Reviews on Advanced Materials Science, vol. 5, no. 2, pp. 134-138, 2003.

[25] A. Afshar, A. G. Dolati, and M. Ghorbani, "Electrochemical characterization of the Ni-Fe alloy electrodeposition from chloride-citrate-glycolic acid solutions," Materials Chemistry and Physics, vol. 77, pp. 352-358, 2002.

[26] Y. M. Yeh, G. C. Tu, and T. H. Fang, "Nanomechanical properties of nanocrystalline Ni-Fe mold insert," Journal of Alloys and Compounds, vol. 372, no. 1-2, pp. 224-230, 2004. 

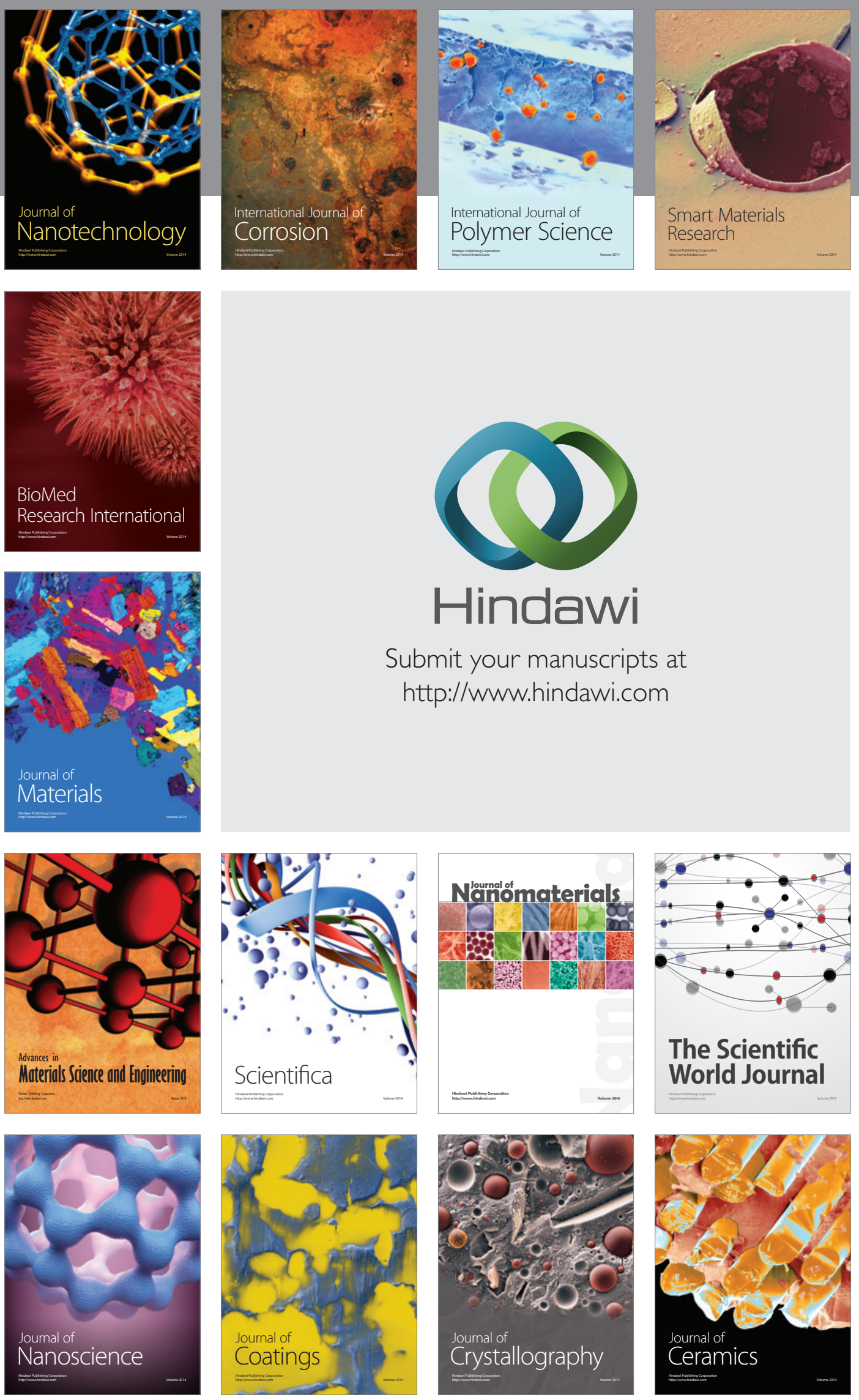

The Scientific World Journal

Submit your manuscripts at

http://www.hindawi.com

\section{World Journal}

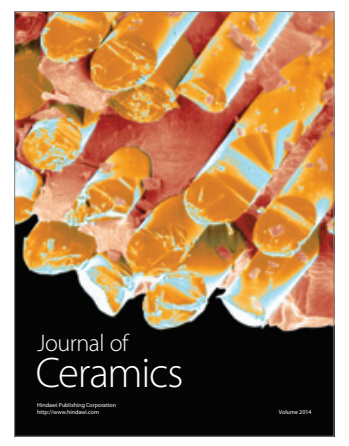

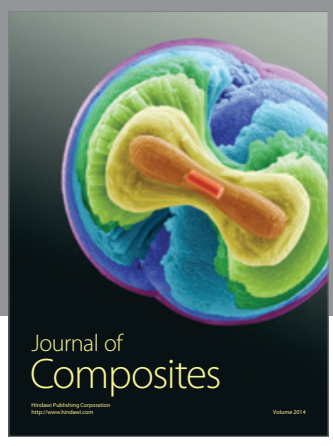
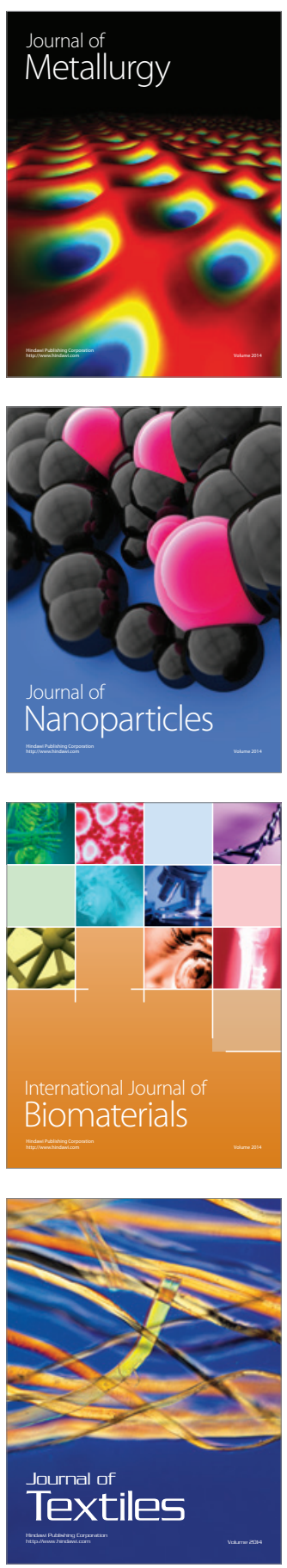